\title{
Post-plateau volcanic evolution of Shatsky Rise (NW Pacific) - Papanin Ridge and Ojin Rise Seamount Province
}

A. DÜRKEFÄLDEN ${ }^{1 *}$, J. GELDMACHER $^{1}, \mathrm{~F}$. $\mathrm{HAUFF}^{1}, \mathrm{D}$. GARBE-SCHÖNBERG $^{2}$, M. PORTNYAGIN ${ }^{1}$, T. LÜCK ${ }^{1}$, R. WERNER $^{1}$, D. MÜLLER ${ }^{3}$ AND K. HOERNLE ${ }^{1,2}$

${ }^{1}$ GEOMAR Helmholtz Centre for Ocean Research Kiel, Wischhofstraße 1-3, 24148 Kiel, Germany

(*correspondence: aduerkefaelden@geomar.de)

${ }^{2}$ Institute of Geosciences, Kiel University, Ludewig-MeynStraße 10, 24118 Kiel, Germany

${ }^{3}$ EarthByte Group, School of Geosciences, University of Sydney, NSW 2006, Australia

Shatsky Rise is an oceanic plateau located in the northwest Pacific Ocean and is assumed to have formed through interaction of a mantle plume with a triple junction (TJ). Finding an age-progressive, intraplate hotspot track associated with the plateau would corroborate this model. Interestingly, two bathymetric features emanate from the youngest end of the main plateau: Papanin Ridge extending to the NE and the scattered Ojin Rise Seamount Province trending towards the SE. Since Papanin Ridge has never been sampled before and only a few Ojin seamounts have been investigated [1,2], we extensively sampled both structures by dredging during R/V SONNE cruise SO265 in 2018 and conducted major and trace element and radiogenic isotope (Sr-Nd-Hf-Pb) analyses in order to decipher their origin and to test if one or both structures represent a probable Shatsky hotspot track.

Papanin Ridge lavas show compositions between N- and E-MORB similar to those from the main plateau implying a generation by the same process (plume-ridge interaction). We assume that the SW part of Papanin Ridge formed along the path of the TJ above the waning plume or by drainage of plume material into the TJ, whereas the NE corner of Papanin Ridge was generated by transient drainage of plume material into the Pacific-Farallon spreading center. The Ojin Rise Seamount Province, in contrast, is geochemically more enriched than Papanin Ridge consistent with representing an intraplate hotspot track being formed by lesser degrees of melting. The seamounts become systematically less enriched from west to east corresponding to decreasing lithospheric thickness towards the east (decreasing distance to the PacificFarallon spreading center).

[1] Tejada et al. (2016) Geochim. Cosmochim. Acta 185, 302327. [2] Sano et al. (in review) Lithos. 